\title{
Biomolecule-Mediated Generation of Ru Nanocatalyst for Sustainable Reduction of Nitrobenzene
}

\author{
Pritam Singh, ${ }^{\dagger}$ Mita Halder, ${ }^{\dagger}$ Santanu Ray, ${ }^{\ddagger}$ Bilwadal Bandyopadhyay, ${ }^{\S}$ and Kamalika Sen ${ }^{*} \dagger \odot$ \\ ${ }^{\dagger}$ Department of Chemistry, University of Calcutta, 92, APC Road, Kolkata 700009, India \\ ${ }^{\ddagger}$ Surface Analysis Laboratory, School of Environment and Technology, University of Brighton, Brighton BN2 4GJ, U.K. \\ ${ }^{\S}$ ECMP Division, NMR Laboratory, Saha Institute of Nuclear Physics, 1/AF Bidhannagar, Kolkata 700064, India
}

Supporting Information

ABSTRACT: A mild and sustainable synthetic route was followed for the generation of biomolecule-assisted $\mathrm{Ru}$ nanocatalyst under open as well as inert atmosphere using the polyphenol morin. The nanocatalyst was characterized thoroughly by powder X-ray diffraction, $\mathrm{N}_{2}$ adsorptiondesorption, high-resolution transmission electron microscopy, dynamic light scattering, X-ray photoelectron spectroscopy, absorption spectroscopy, Fourier transform infrared spectroscopy, fluorescence spectroscopy, thermogravimetric analysis, and inductively coupled plasma optical emission spectrometry. The nanocatalyst reveals excellent catalytic activity for the reduction of several substituted nitrobenzene to aniline derivatives under simple, mild, and environment-friendly conditions. The catalyst can be reused for four consecutive cycles without significant loss in its catalytic activity.

\section{INTRODUCTION}

Study related to nanocatalysts (NCs) is one of the most attractive and frontline areas of modern research due to their diverse applications in innumerable branches of science. The unique properties of NCs, including large surface-to-volume ratio and numerous accessible active sites compared to their bulk counterparts, make these materials most favorable for organic transformations. Organic transformations using NCs are in vogue as they offer several benefits like excellent atom economy, placid reaction conditions, ease of separation of the synthesized products as well as catalysts, etc. ${ }^{1-3}$ Therefore, extensive research for efficient design and sustainable production of highly active metal or metal oxide NCs is exceedingly worthwhile. Several literature reports are available describing novel methods for the synthesis of metal-based NCs. $^{4-8}$ Nanodimensional noble metals, mainly palladium, platinum, and ruthenium have captured significant interest, due to their high activity and selectivity toward several catalytic processes, 9,10 including selective hydrogenation of chloro nitrobenzene $(p-\mathrm{CNB}) .{ }^{11}$ Although ruthenium is a low-cost material, a recyclable Ru-based catalyst would make the methodology many-fold cost-effective, environment-friendly, and industrially efficient. The widely studied methods for the generation of nanodimensional $\mathrm{Ru}$ catalyst utilize the conventional reduction process with drastic reaction conditions. ${ }^{1,12}$

Reduction using biomolecules has gradually captured the limelight of researchers due to the increasing environmental, economic, as well as industrial concern. In this connection, plant extract or plant-mediated materials have revealed their

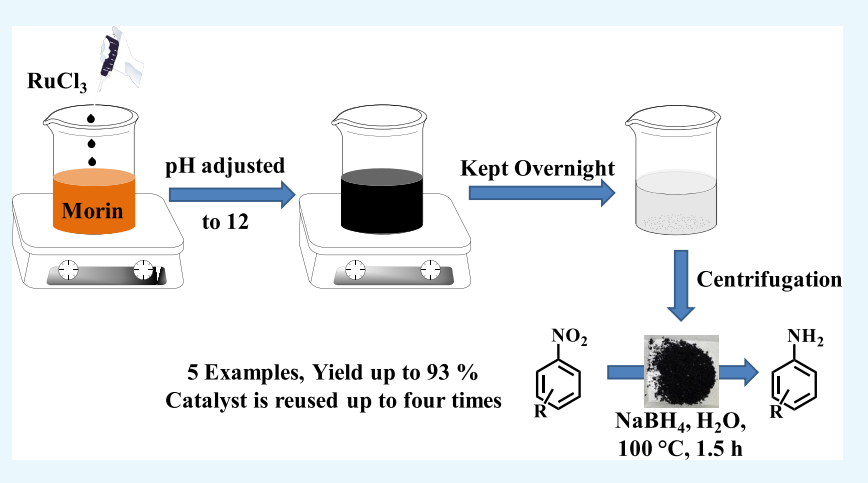

capability to convert metal ions into their nanostate often through a simple process without requirement of any rigorous experimental setup. Significantly, phytochemicals like polyphenols, phenolic acids, alkaloids, terpenoids, sugars, etc., present in plant metabolites, probably partake in the biosynthesis of metal and/or metal oxide nanoparticles (NPs). In an effort to harness such nanodimensional $\mathrm{Ru}$, Kannan and Sundrarajan have reported the synthesis of ruthenium oxide NPs using Acalypha indica plant extract, ${ }^{13}$ wherein they studied the antimicrobial activity of the NPs. Ismail et al. have reported a green synthesis of ruthenium oxide NPs using aqueous extract of Aspalathus linearis and deposited over nickel foam to develop a supercapacitor. ${ }^{14}$ Synthesis of $\mathrm{Se} / \mathrm{Ru}$ alloy was reported by $\mathrm{Zhou}$ et al., with the help of gallic acid as both reducing and stabilizing agent, ${ }^{15}$ which was further studied for the possibility of its biomedical applications. Reports on green syntheses of nanodimensional ruthenium for catalytic applications are scarce excepting a few. ${ }^{16,17}$ Generation of nanodimensional $\mathrm{Ru}$ employing the vast family of biomolecules still remains to be unveiled and explored for their magnificent catalytic properties. Some literature reports are tabulated here, which describe the syntheses of Ru-NCs under different conditions (Table 1).

Formation of aniline derivatives is of significant interest due to the pharmaceutical as well as industrial concerns. ${ }^{20,21}$

Received: August 27, 2019

Accepted: November 18, 2019

Published: December 4, 2019 
Table 1. List of Some Possible Ways of Synthesis of Ru NCs Found in the Literature

\begin{tabular}{|c|c|c|c|}
\hline entry & synthetic condition & $\begin{array}{l}\text { oxidation } \\
\text { state of } \mathrm{Ru}\end{array}$ & ref \\
\hline 1 & $\begin{array}{l}\text { Aqueous solution of } \mathrm{RuCl}_{3} \text { and } \mathrm{A} \text {. indica leaf extract were mixed and then stirred at } 80{ }^{\circ} \mathrm{C} \text { for } 2 \mathrm{~h} \text {. The solid mass was collected after } \\
\text { centrifugation. Finally, the nanomaterial was obtained after calcination at } 600{ }^{\circ} \mathrm{C} \text {; }\end{array}$ & IV & 13 \\
\hline 2 & $\begin{array}{l}\mathrm{RuCl}_{3} \text { aqueous solution was added to Aspalathus linearis extract at } \mathrm{pH} 3.8 \text {. Then, the mixture was stirred at room temperature with } \\
\text { reaction time } 2 \mathrm{~h} \text {; }\end{array}$ & IV & 14 \\
\hline 3 & $\begin{array}{l}\text { Aqueous solution of gallic acid, } \mathrm{Na}_{2} \mathrm{SeO}_{3} \text {, and } \mathrm{RuCl}_{3} \text { were mixed together at } \mathrm{pH} 3 \text { under heating at } 70{ }^{\circ} \mathrm{C} \text {. The excess gallic acid and } \\
\mathrm{Na}_{2} \mathrm{SeO}_{3} \text { were removed by dialysis; }\end{array}$ & & 15 \\
\hline 4 & $\begin{array}{l}\mathrm{RuCl}_{3} \text { was taken in colloidal aqueous solution of graphene oxide. The mixture was stirred for } 1 \mathrm{~h} \text {. After heating at } 400{ }^{\circ} \mathrm{C} \text { for } 2 \mathrm{~h} \text { in an } \\
\text { autoclave, the solid was washed and dried at } 60^{\circ} \mathrm{C} \text {; }\end{array}$ & & 17 \\
\hline 5 & $\begin{array}{l}\text { Solid } \mathrm{RuCl}_{3} \text { was mixed thoroughly with solid } \mathrm{NaBH}_{4} \text { under solventless condition. The mixture was washed with ethanol and centrifuge } \\
\text { to collect the solid mass. Finally, the solvent was removed through vacuum drying; }\end{array}$ & 0 & 18 \\
\hline 6 & $\begin{array}{l}\text { Silica support was added to aqueous solution of } \mathrm{RuCl}_{3} \text {. The mixture was sonicated. } \mathrm{NaBH}_{4} \text { solution was added to this suspension with } \\
\text { stirring. The solid mass was separated using a magnet, washed with water, and finally vacuum-dried at } 60{ }^{\circ} \mathrm{C} \text {. }\end{array}$ & 0 & 19 \\
\hline
\end{tabular}

Aniline and its derivatives widely participate in the synthesis of several valuable compounds, including pharmaceuticals, pigments, pesticides, herbicides, rigid polyurethane, etc. ${ }^{20-23}$ Aniline acts as the building block for the synthesis of different peptides, amino acids, etc. ${ }^{24}$ Moreover, synthesis of aniline derivatives is crucial due to its manifold applications in various fields such as production of consumer goods, adhesives/ sealants, coatings, textile materials, pulp and care, rubber products, electronic goods, etc. ${ }^{25}$ Aromatic amines are usually prepared from catalytic reduction of nitroarenes in the presence of $\mathrm{H}_{2}$ gas, $\mathrm{NaBH}_{4}$, and $\mathrm{N}_{2} \mathrm{H}_{4}$ as reducing agent together with a catalyst, viz., ruthenium, SBA-15, carbon nanotubes, etc. ${ }^{26-36}$

In the present study, we have described an efficient green synthesis of ruthenium nanocatalysts using a flavonoid-type biomolecule, morin as stabilizing agent at room temperature (Scheme 1). The synthesis has been done both in open

Scheme 1. General Reaction Scheme for the Reduction of Nitrobenzene to Aniline Using Ruthenium-NCs

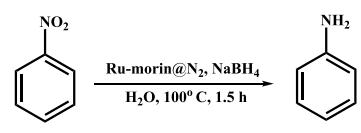

atmosphere and in $\mathrm{N}_{2}$ environment. Morin is a naturally available polyphenol commonly obtained from Maclura pomifera and Maclura tinctoria and from the leaves of Psidium guajava. ${ }^{37}$ It can act as a reducing as well as stabilizing agent during nanosynthesis. Thereafter, the as-synthesized nanomaterials have been employed for the reduction of nitroarenes to furnish aromatic amines and their derivatives with good to excellent product yields.

\section{CHARACTERIZATION}

Absorption Spectroscopy. Absorption spectroscopy was used to find the best condition for the preparation of NCs. The time scan data established the possible mechanism behind the formation of the NCs. To get the best condition of NC formation, $0.2 \mathrm{~mL}$ of $10 \mathrm{mM}$ alcoholic solution of morin was taken in $2.5 \mathrm{~mL}$ solution of different $\mathrm{pH}$ values (viz., 5, 7, 9, and 12). The alcoholic solution of morin has its characteristic absorption maximum at $\sim 330 \mathrm{~nm}$. Then, $0.01 \mathrm{~mL}$ portion of 1 $\mathrm{mM} \mathrm{RuCl}_{3}$ solution was gradually added to the above morincontaining solution of different $\mathrm{pH}$ values.

$\mathrm{N}_{2}$ Adsorption-Desorption and BET Analysis. $\mathrm{N}_{2}$ adsorption-desorption was performed using the solid sample to determine the specific surface properties of the material.
The specific surface area, pore size distribution, and pore volume of the solid material can be obtained after degassing the material at $300{ }^{\circ} \mathrm{C}$ in a surface area analyzer instrument for 3 h. Finally, the specific surface area of the NCs can also be obtained using Brunauer-Emmett-Teller (BET) method.

TEM analysis. The TEM analysis was performed after dispersing $2 \mathrm{mg}$ of the $\mathrm{NC}$ in $2 \mathrm{~mL}$ of water-alcohol (1:1) mixture and sonicating for $1 \mathrm{~h}$. Then, the dispersed solution was drop-cast on a carbon-coated $\mathrm{Cu}$ grid. Before getting the TEM images of the material, the grid was dried under an IR lamp.

FTIR Analysis. FTIR analysis was used to get an idea about the bond vibrations of the NCs. A very small amount of the solid material was thoroughly mixed with dry $\mathrm{KBr}$ using a mortar and pestle. The sample was then pelletized using pressure around 5 ton using a hydraulic press. The pellet was then loaded in the sample holder of the analyzer instrument.

Powder XRD. Powder XRD was used to determine the crystalline nature of the prepared NCs. Powder sample was taken in a rectangular metal holder and then the arrangement was lightly pressed before the X-ray crystallographic analysis.

Dynamic Light Scattering (DLS). Dynamic light scattering experiment was carried out to estimate the hydrodynamic radii of the NCs. The sample preparation method is similar to that of the TEM experiment. The dispersed solution obtained after sonication for $1 \mathrm{~h}$ was further diluted $\sim 100$ times to perform the experiment.

Thermogravimetric Analysis (TGA). The thermal properties of the $\mathrm{NC}$ were determined using the thermogravimetric analysis technique under $\mathrm{N}_{2}$ atmosphere with a flow rate of 10 $\mathrm{mL} / \mathrm{min}$. An $\sim 6 \mathrm{mg}$ of solid sample was taken on a platinum pan and heated to $\sim 439{ }^{\circ} \mathrm{C}$ at a heating rate of $10{ }^{\circ} \mathrm{C} / \mathrm{min}$ to record the change of weight percentage with the change of temperature.

X-ray Photoelectron Spectroscopy (XPS) Analysis. The elemental composition and the oxidation state of the central metal ion were analyzed using this technique. A monochromated $\mathrm{Al} \mathrm{K} \alpha$ was used as X-ray source with $\mathrm{X}$-ray spot size of $900 \times 900 \mu \mathrm{m}^{2}$ outfitted with the XPS instrument. A flood gun was used for uniform charge neutralization. The binding energies (BEs) of $\mathrm{Ru} 3 \mathrm{~d}(\sim 280 \mathrm{eV}), \mathrm{C} 1 \mathrm{~s}(\sim 285 \mathrm{eV})$, $\mathrm{N}$ 1s $(\sim 400 \mathrm{eV})$, and $\mathrm{O} 1 \mathrm{~s}(\sim 531 \mathrm{eV})$ were obtained using both full survey and narrow scan methods. The full survey scan was repeated five times with step size of $1 \mathrm{eV}$, pass energy of $150 \mathrm{eV}$, and dwell time of $50 \mathrm{~ms}$, whereas the narrow scan was repeated 15 times with step size and pass energy of 0.1 and 20 $\mathrm{eV}$, respectively, and dwell time of $100 \mathrm{~ms}$. Due to the very close binding energy of $\mathrm{Ru} 3 \mathrm{~d}$ and $\mathrm{C} 1 \mathrm{~s}, \mathrm{Ru} 3 \mathrm{p}(\mathrm{BE} \sim 475 \mathrm{eV})$ 
was also acquired using the narrow scan method. All of the data were examined using Thermo Avantage Software (version 5.952) taking a smart background.

ICP-OES Analysis. Inductively coupled plasma optical emission spectrometry (ICP-OES) was used to determine the amount of ruthenium in the catalyst and also the leaching percentage of the $\mathrm{Ru}$ from the catalyst after the reaction. To get the amount of ruthenium in the catalyst, $6 \mathrm{mg}$ of solid catalyst was digested in hot and concentrated $\mathrm{HNO}_{3}$. To achieve leaching of the catalyst, $6 \mathrm{mg}$ of the catalyst was treated with nitrobenzene, water, and reducing agent as in the reaction mixture (as described in the following section). After the reaction was complete, the reaction mixture was centrifuged. The reaction mixture was collected separately, and the solid catalyst was again washed with water and then centrifuged again. Finally, the reaction mixture was digested with hot and concentrated $\mathrm{HNO}_{3}$. After three successive addition and evaporation of concentrated acid, the solid masses so obtained were cooled to room temperature. Finally, the solid masses were treated with a requisite amount of Milli-Q water. Then, the aqueous solutions were filtered using a microsyringe filter (pore size, $0.22 \mu \mathrm{m}$ ). The filtrates were then diluted with water to a particular volume, and then the solutions were introduced in the ICP-OES instrument.

Catalytic Activity for Reduction of Nitrobenzene to Aniline. The NCs designated as Ru-morin@air and Rumorin@ $\mathrm{N}_{2}$ were studied for their catalytic activities toward reduction of nitrobenzene to aniline in the presence of $\mathrm{NaBH}_{4}$ as a reducing agent and water as a solvent at $100{ }^{\circ} \mathrm{C}$. After completion of the reaction (as indicated by TLC), and separation of the catalyst, the reaction mixture was extracted using ethyl acetate $(3 \times 10 \mathrm{~mL})$. The organic part was washed with water and dried using anhydrous sodium sulfate. Then, the solvent was evaporated under reduced pressure to get the solid mass that was purified by column chromatography using pet ether and ethyl acetate as eluent to get the pure product. The identity of the product was confirmed by ${ }^{1} \mathrm{H}$ and ${ }^{13} \mathrm{C}$ NMR spectroscopy.

Recycling Experiment. At the end of the reaction, Rumorin@ $\mathrm{N}_{2} \mathrm{NC}$ was separated from the reaction medium by centrifugation. Particularly, Ru-morin@ $\mathrm{N}_{2} \mathrm{NC}$ was chosen for the recycling experiment as it showed better catalytic activity. The collected NC was repetitively rinsed with water and ethyl acetate, followed by diethyl ether. Finally, the NC was dried at $80{ }^{\circ} \mathrm{C}$ temperature for $1 \mathrm{~h}$ to activate for the next run.

\section{RESULTS AND DISCUSSION}

Absorption Spectroscopy. The best condition for the formation of the $\mathrm{NC}$ was $\mathrm{pH} 12$, as indicated by the absorption spectra. At this $\mathrm{pH}$, a sharp increase in the absorbance $\left(\lambda_{\max }=\right.$ $330 \mathrm{~nm}$ ) occurred with gradual addition of $\mathrm{RuCl}_{3}$ solution to the morin solution of $\mathrm{pH} 12$. The Benesi-Hildebrand $(\mathrm{B}-\mathrm{H})$ (Figure 1 and inset) plot indicates that the stoichiometry and the association constant for the interaction between ruthenium and morin at $\mathrm{pH} 12$ were $1: 1$ and $1235.83 \mathrm{M}^{-1}$, respectively, using eq 1

$$
\frac{1}{A-A_{0}}=\frac{1}{A_{1}-A_{0}}+\frac{1}{\left(A_{1}-A_{0}\right) K_{\mathrm{a}}[\mathrm{M}]}
$$

where $A_{0}$ is the absorbance of morin solution in the absence of ruthenium, $A_{1}$ is the absorbance of morin solution when it is completely bound with ruthenium, $A$ is the absorbance of

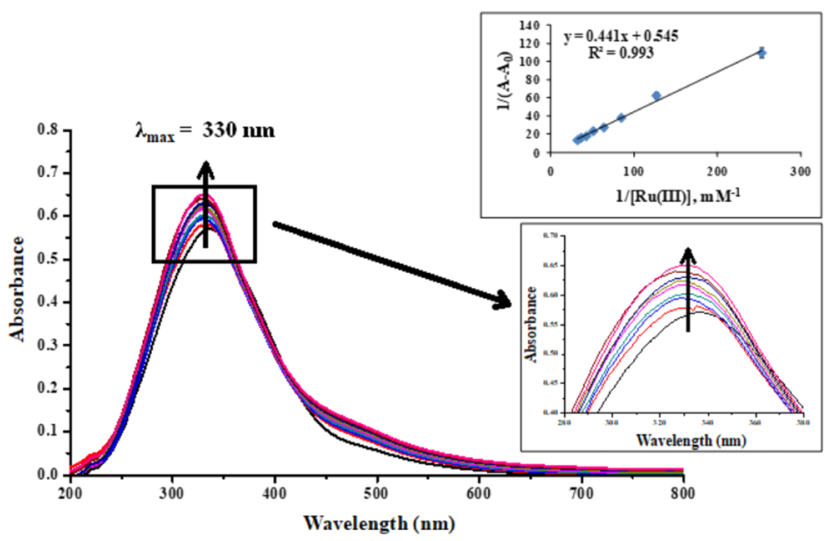

Figure 1. UV interaction data and $\mathrm{B}-\mathrm{H}$ plot (inset) between morin $(79-76 \mu \mathrm{M})$ and ruthenium $(4-30 \mu \mathrm{M})$ at $\mathrm{pH} 12$.

morin solution with gradual addition of ruthenium, $[\mathrm{M}]$ is the concentration of ruthenium, and $K_{\mathrm{a}}$ is the binding or association constant. ${ }^{38}$

The absorption spectral changes of morin solution at $\mathrm{pH}$ values 5, 7, and 9 with increasing $\mathrm{Ru}$ concentration were insignificant and are pictorially described in supplementary figures (Figures S1-S3).

Mechanism of Formation of NCs. The possible mechanism for the formation of NC was established using time-dependent absorption spectroscopy. To study the mechanism, the metal solution and alcoholic solution of morin were taken in equimolar ratio at $\mathrm{pH} 12$ in a cuvette and then the absorbance value of the resulting solution was measured at $330 \mathrm{~nm}$ continuously up to $4.5 \mathrm{~h}$ (Figure 2). The

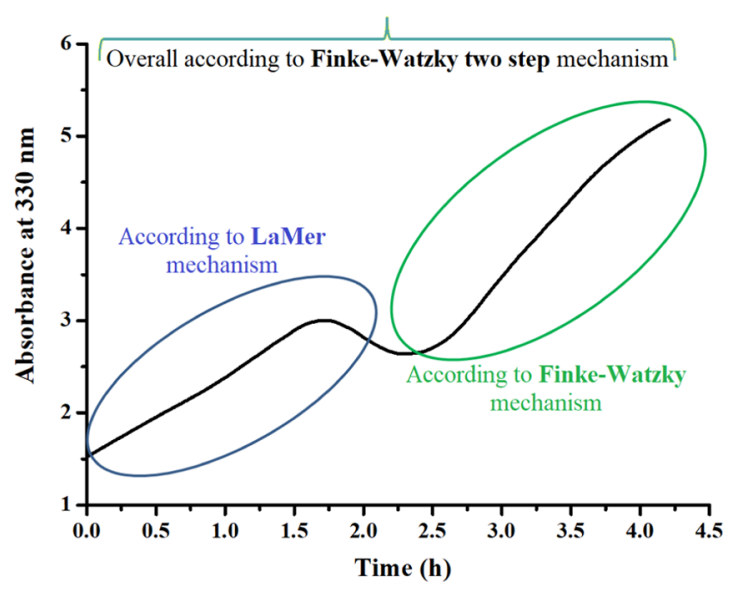

Figure 2. Time scan profile for Ru-morin@air NC material at pH 12.

initial hike followed by achieving a maximum suggested an increase in monomer concentration which resulted due to burst nucleation governed by the LaMer mechanism. Thereafter, a steady increase in the absorbance for ruthenium-morin $\mathrm{NC}$ proposed a rapid autocatalytic growth according to the Finke-Watzky model. ${ }^{39}$

$\mathrm{N}_{2}$ Adsorption-Desorption and BET Analysis. The catalytic activity of porous materials may be related to their surface activity, which is again dependent on their pore diameter. This can be found in agreement with earlier studies. $^{40,41}$ The catalyst in this was also found to be mesoporous as can be seen from the results of BET analysis. Figure 3 represents the $\mathrm{N}_{2}$ adsorption-desorption curve of the 

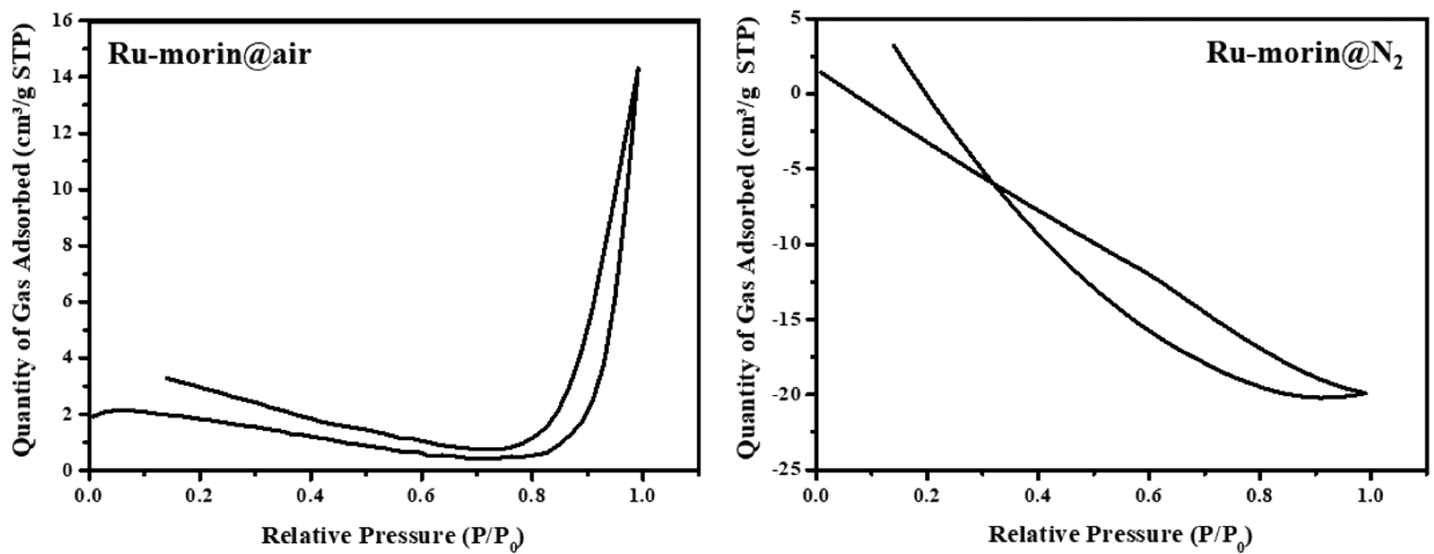

Figure 3. $\mathrm{N}_{2}$ adsorption-desorption isotherm of Ru-morin@air and Ru-morin@ $\mathrm{N}_{2} \mathrm{NCs}$.

Ru-morin@air and Ru-morin@ $\mathrm{N}_{2}$ NCs. From the figure, it is clear that the surface properties of Ru-morin@air show a convex type of isotherm with a blunt knee at a lower $P / P_{0}$ value and an elevated adsorption at higher $P / P_{0}$ value. This type of isotherm (type II) is generally obtained for unhampered monolayer-multilayer adsorption at high $P / P_{0}$. The small knee indicates a major overlap of monolayer adsorption and initiation of multilayer adsorption. The width of the adsorption layer increased at $P / P_{0}=1$. An $\mathrm{H} 3$ hysteresis loop was obtained for Ru-morin@air which is typical for nonrigid platelike assembly at the surface of the NCs. The adsorption-desorption study for Ru-morin@ $\mathrm{N}_{2}$ shows type IV isotherm with $\mathrm{H} 4$ hysteresis loop. This type of isotherm is common for mesoporous adsorbent in which the adsorbentadsorptive interaction plays a key role in determining the adsorption behavior of the adsorbent. Similar to type II isotherm, the monolayer-multilayer adsorption takes place by the pore condensation phenomenon. The H4 hysteresis loop has the characteristics of aggregated particles as obtained from TEM study also (discussed in the following section). ${ }^{42}$ For Rumorin@ $\mathrm{N}_{2}$, the change of the nature of the isotherm and the hysteresis loop is also in agreement with the change of surface morphology in inert atmosphere. ${ }^{43}$ The BET specific surface areas of Ru-morin@air and Ru-morin@ $\mathrm{N}_{2} \mathrm{NCs}$ are 4.72 and $24.11 \mathrm{~m}^{2} / \mathrm{g}$, respectively. The porous nature of each of the adsorbent is obtained from this characterization and shows the average pore diameter for Ru-morin@air and Ru-morin@ $\mathrm{N}_{2}$ to be 8.33 and $7.82 \mathrm{~nm}$, respectively.

TEM Analysis. Figure 4 represents the TEM images of the prepared NCs, Ru-morin@air, and Ru-morin@ $\mathrm{N}_{2}$ and confirms that they are formed in nanodimensions. The TEM images indicate significant differences for Ru-morin@air and Ru-morin@N . For Ru-morin@air, frail lattice fringes with nanocrystalline and fine porosity were observed. However, for

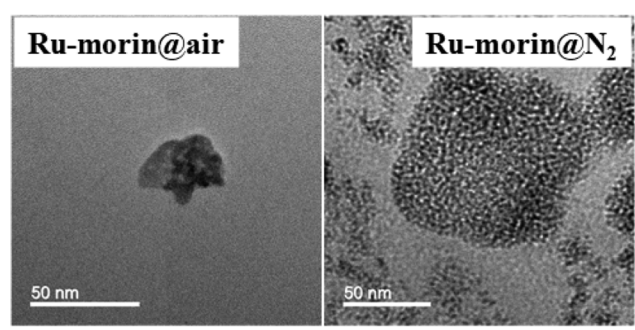

Figure 4. TEM images of Ru-morin@air and Ru-morin@ $\mathrm{N}_{2}$ NCs.
Ru-morin@ $\mathrm{N}_{2}$, the TEM image shows an aggregated mass of the NCs with hardly any nanocrystallinity. The selected area electron diffraction (SAED) pattern (Figure 5) of the NCs

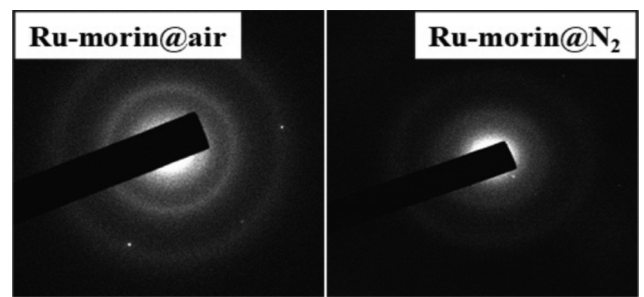

Figure 5. SAED pattern of Ru-morin@air and Ru-morin@ $\mathrm{N}_{2}$ NCs.

reflected the same observation as from the TEM images. The particle size of the NCs was estimated using histogram analysis. From the histogram data, we obtained that the average particle size of Ru-morin@air and Ru-morin@ $\mathrm{N}_{2}$ lies in the range of 20-10 $\mathrm{nm}$ (Figure 6). There is a slight decrease in average particle size in $\mathrm{N}_{2}$ atmosphere. However, there is an enhanced tendency for agglomeration in inert atmosphere, which arises due to higher interparticle interactions in the inert atmosphere. $^{43,44}$ These results are in good agreement with the literature reports that suggest the change of surface morphology with the implementation of inert atmosphere.

FTIR Analysis. To get information about the bond vibrations of the NCs, the solid-state FTIR spectroscopy was performed. We tried to compare the bond frequencies present in the NC to that of the pure morin molecule to get a clear idea about the change, appearance, or disappearance of bond vibrations. Figure 7 represents the FTIR spectra of pure morin, Ru-morin@air, and Ru-morin@ $\mathrm{N}_{2}$ NCs. On inspection of the three spectra, we found that, on NC formation, a clear change is observed in the $1612-831 \mathrm{~cm}^{-1}$ region. For Ru-morin@air, the peak at $1612 \mathrm{~cm}^{-1}$ for $\mathrm{C}=\mathrm{C}$ stretching vibration present in morin was shifted to $1619 \mathrm{~cm}^{-1}$. The two peaks at 1515 and $1445 \mathrm{~cm}^{-1}$ for aromatic $\mathrm{C}=\mathrm{C}$ stretching and in-plane $\mathrm{C}-\mathrm{C}-$ $\mathrm{H}$ bending present in morin moiety completely disappeared in Ru-morin@air. The peak at $1376 \mathrm{~cm}^{-1}$ for $-\mathrm{OH}$ bending vibration and in-plane bending vibration of the $\mathrm{C}-\mathrm{O}-\mathrm{H}$ group present in morin molecule was shifted to $1383 \mathrm{~cm}^{-1}$ in $\mathrm{Ru}-$ morin@air. Two peaks of morin at 1294 and $1163 \mathrm{~cm}^{-1}$ for asymmetric stretching of $\mathrm{Ph}-\mathrm{O}$ bond and aromatic $\mathrm{C}-\mathrm{H}$ bending, respectively, absolutely disappeared in Ru-morin@air. Rather a new peak at $1121 \mathrm{~cm}^{-1}$ for in-plane $\mathrm{C}-\mathrm{H}$ bending 

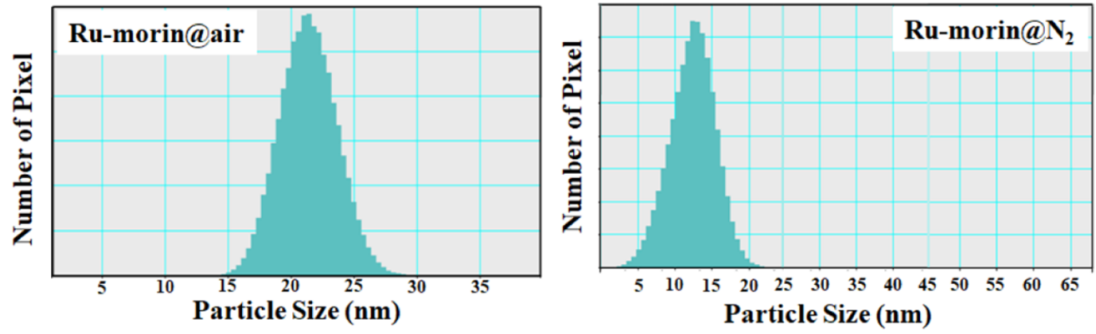

Figure 6. Histogram of Ru-morin@air and Ru-morin@ $\mathrm{N}_{2} \mathrm{NCs}$.

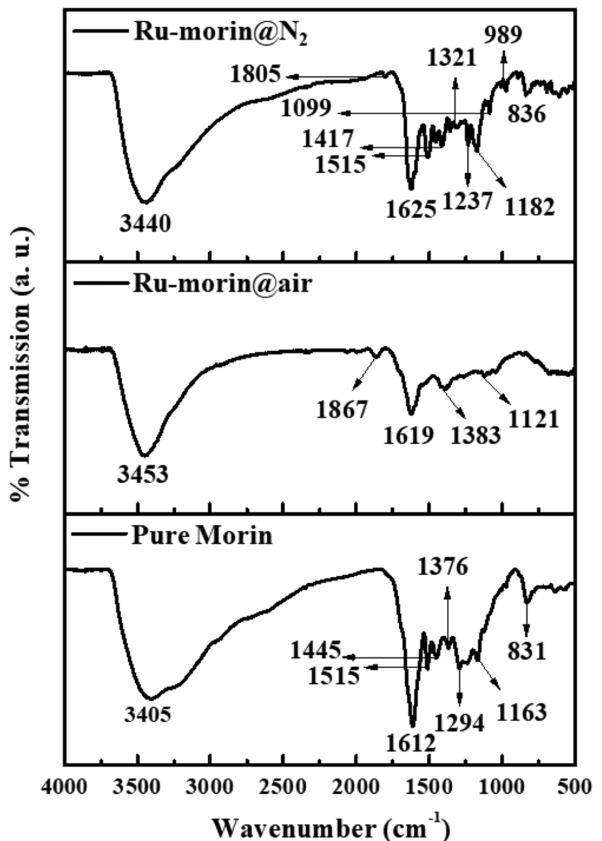

Figure 7. FTIR spectra of pure morin, Ru-morin@air, and Rumorin@ $\mathrm{N}_{2}$ NCs.

vibration appeared upon NC formation in open atmosphere (Ru-morin@air). Another new peak at $1867 \mathrm{~cm}^{-1}$ appeared due to metal-CO bond vibration in Ru-morin@air NC. The peak at $831 \mathrm{~cm}^{-1}$ for twisting vibration of the $\mathrm{C}-\mathrm{O}$ bond was absent in the NC materials. For Ru-morin@ $\mathrm{N}_{2}$, although the change in bond frequency is less prominent than that for $\mathrm{Ru}-$ morin@air, yet we tried to elaborate the situation. The peak at $1612 \mathrm{~cm}^{-1}$ in morin was shifted to $1625 \mathrm{~cm}^{-1}$ in the Rumorin@ $\mathrm{N}_{2}$ NCs. The peak at $1515 \mathrm{~cm}^{-1}$ in the morin moiety remained unaltered on NC formation, whereas the intensity of the peak at $1445 \mathrm{~cm}^{-1}$ was measurably lowered and a new peak at $1417 \mathrm{~cm}^{-1}$ appeared in the NC. The peak at $1294 \mathrm{~cm}^{-1}$ in morin was missing in the $\mathrm{NC}$, rather a new peak at $1237 \mathrm{~cm}^{-1}$ appeared due to bending vibration of $\mathrm{CH}_{2}$ group in the NC. The peak at $1376 \mathrm{~cm}^{-1}$ disappeared and a new peak at 1321 $\mathrm{cm}^{-1}$ appeared owing to $=\mathrm{C}-\mathrm{H}$ bending vibration in the NC. The peak at $1163 \mathrm{~cm}^{-1}$ in the morin was shifted to $1182 \mathrm{~cm}^{-1}$ upon NC formation. Another new peak at $989 \mathrm{~cm}^{-1}$ due to C$\mathrm{H}$ bond vibration appeared in the Ru-morin@ $\mathrm{N}_{2} \mathrm{NC}$. The peak at $831 \mathrm{~cm}^{-1}$ in morin was shifted to $836 \mathrm{~cm}^{-1}$ in the $\mathrm{Ru}$ morin@ $\mathrm{N}_{2} \mathrm{NC}$ material. One new peak at $1805 \mathrm{~cm}^{-1}$ appeared in this $\mathrm{NC}$ owing to the metal-CO bond vibration. The results with individual band identifications are presented in Table 2. The FTIR data suggest that although there is bonding between functionalities of morin and metal, no subsequent oxidation of
Table 2. FTIR Spectral Data of the Pure Morin, Ru-morin@ air, and Ru-morin@ $\mathrm{N}_{2}$ NCs with Their Possible Functionalities

\begin{tabular}{|c|c|c|}
\hline sample & $\begin{array}{c}\text { peak } \\
\text { position } \\
\left(\mathrm{cm}^{-1}\right)\end{array}$ & functionality \\
\hline \multirow[t]{11}{*}{ Ru-morin@N 2} & 3440 & $\mathrm{O}-\mathrm{H}$ group stretching frequency ${ }^{13}$ \\
\hline & 1805 & metal- $\mathrm{CO}$ bond frequency ${ }^{45}$ \\
\hline & 1625 & $\mathrm{C}=\mathrm{C}$ or $\mathrm{C}=\mathrm{O}$ bond vibration ${ }^{45,46}$ \\
\hline & 1515 & aromatic $\mathrm{C}=\mathrm{C}$ stretching and in-plane \\
\hline & 1417 & $\mathrm{C}-\mathrm{C}-\mathrm{H}$ bending ${ }^{4,48}$ \\
\hline & 1321 & $=\mathrm{C}-\mathrm{H}$ bending ${ }^{45}$ \\
\hline & 1237 & bending vibration of $\mathrm{CH}_{2}$ group ${ }^{49}$ \\
\hline & 1182 & aromatic $\mathrm{C}-\mathrm{H}$ bending ${ }^{50}$ \\
\hline & 1099 & $\mathrm{C}-\mathrm{O}-\mathrm{C}$ asymmetric stretching ${ }^{50}$ \\
\hline & 989 & vibrational frequency for $\mathrm{C}-\mathrm{H}$ bond ${ }^{50}$ \\
\hline & 836 & twisting of $\mathrm{C}-\mathrm{O}$ bond $^{51}$ \\
\hline \multirow[t]{5}{*}{ Ru-morin@air } & 3453 & $\mathrm{O}-\mathrm{H}$ group stretching frequency ${ }^{13}$ \\
\hline & 1867 & metal-CO bond frequency ${ }^{45}$ \\
\hline & 1619 & $\mathrm{C}=\mathrm{C}$ bond vibration ${ }^{45,46}$ \\
\hline & 1383 & $\begin{array}{l}-\mathrm{OH} \text { bending vibration and in-plane } \\
\text { bending vibration of } \mathrm{C}-\mathrm{O}-\mathrm{H} \text { group }\end{array}$ \\
\hline & 1121 & in-plane $\mathrm{C}-\mathrm{H}$ bending vibration ${ }^{52}$ \\
\hline \multirow[t]{8}{*}{ pure morin } & 3405 & $\begin{array}{l}\text { broad, due to } \mathrm{H} \text {-bonded } \mathrm{O}-\mathrm{H} \text { group } \\
\text { stretching frequency }{ }^{13}\end{array}$ \\
\hline & 1612 & $\mathrm{C}=\mathrm{C}$ stretching frequency ${ }^{45,46}$ \\
\hline & 1515 & $\begin{array}{l}\text { aromatic } \mathrm{C}=\mathrm{C} \text { stretching and in-plane } \\
\mathrm{C}-\mathrm{C}-\mathrm{H} \text { bending } \\
47,48\end{array}$ \\
\hline & 1445 & \\
\hline & 1376 & $\begin{array}{l}-\mathrm{OH} \text { bending vibration and in-plane } \\
\text { bending vibration of } \mathrm{C}-\mathrm{O}-\mathrm{H} \text { group }\end{array}$ \\
\hline & 1294 & asymmetric stretching of $\mathrm{Ph}-\mathrm{O}$ bond $^{50}$ \\
\hline & 1163 & aromatic $\mathrm{C}-\mathrm{H}$ bending $^{50}$ \\
\hline & 831 & twisting of $\mathrm{C}-\mathrm{O}$ bond $^{51}$ \\
\hline
\end{tabular}

morin could be observed, suggesting that morin is acting as a stabilizing agent.

Powder XRD. Figure S4 represents the powder X-ray diffraction pattern of Ru-morin@air and Ru-morin@ $\mathrm{N}_{2} \mathrm{NCs}$. No major diffraction pattern in the PXRD of either of the two materials was observed. Although the TEM image and SAED pattern of Ru-morin@air indicate the nanocrystalline nature of the material, the PXRD pattern grossly reflects its amorphous nature. This can be attributed to the experimental setup of the two characterization tools. For TEM or SAED, we generally focus on a very particular portion of the $\mathrm{NC}$ in its microenvironment. But for PXRD, the result is basically the average behavior of a larger portion of the material. For $\mathrm{Ru}-$ morin@ $\mathrm{N}_{2}$, both the results are in agreement with each other and indicate the amorphous nature of the material.

DLS Measurement. From DLS analysis, the hydrodynamic radii of Ru-morin@air and Ru-morin@ $\mathrm{N}_{2} \mathrm{NCs}$ were obtained 
as 614 and $46 \mathrm{~nm}$, respectively (Figure 8). The anomalies in the particle size compared to the TEM experiment are due to

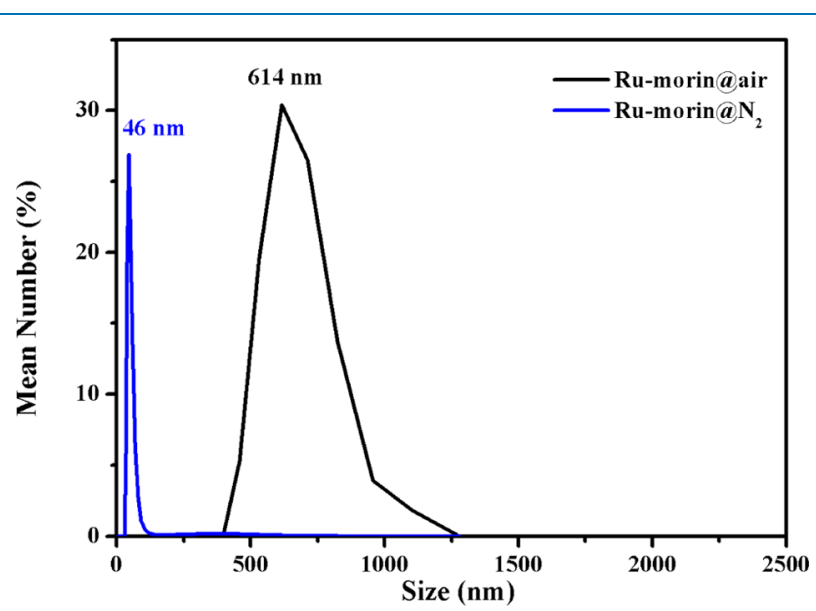

Figure 8. DLS pattern of Ru-morin@air and Ru-morin@ $\mathrm{N}_{2}$ NCs.

the enhanced hydrodynamic radius of the NCs in solution phase present in the colloidal solution. ${ }^{53}$ The larger increase in the hydrodynamic radius for Ru-morin@air compared to Rumorin@ $\mathrm{N}_{2}$ may be attributed to the involvement of oxygen in the atmosphere that results in the generation of oxide-type particles with a resultant increase in the hydration environment. This trend in deviation is in good agreement with the results obtained from TEM experiment.

TGA Analysis. Figure 9 describes the TGA graph of the Ru-morin@ $\mathrm{N}_{2}$ NC. The plot shows a gradual weight loss of

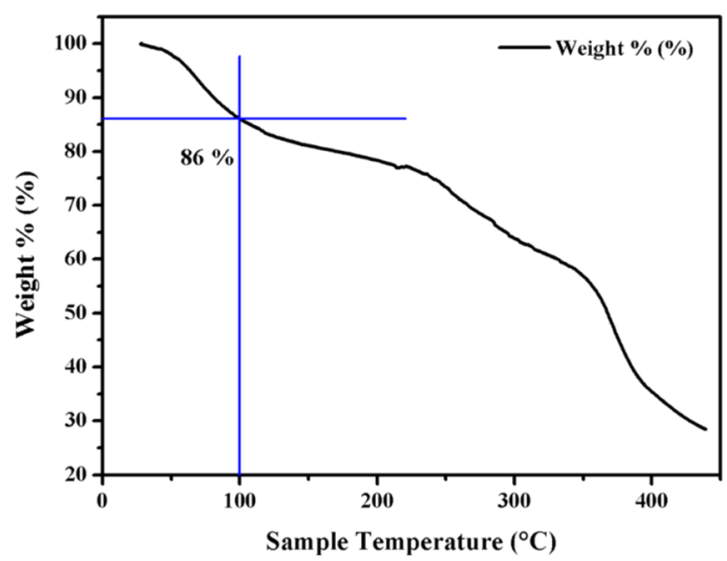

Figure 9. TGA graph for Ru-morin@ $\mathrm{N}_{2} \mathrm{NC}$.

the NC with the increase of temperature. But it is only $14 \%$ from the ambient temperature to $100{ }^{\circ} \mathrm{C}$, which may be due to the presence of polyphenol moiety, which degrades upon heating. Although a significant mass loss was observed after $200{ }^{\circ} \mathrm{C}$, as our reaction is carried out at $\sim 100{ }^{\circ} \mathrm{C}$, we can say that up to this temperature, the catalyst is stable enough and is able to catalyze the reaction successfully.

XPS Data. The narrow scan XPS images of Ru $3 \mathrm{~d}$ and C $1 \mathrm{~s}$ of the two NCs are plotted in Figure 10. In spite of very close proximity of $\mathrm{Ru} 3 \mathrm{~d}$ and $\mathrm{C} 1 \mathrm{~s}$ binding energy, $\mathrm{Ru} 3 \mathrm{~d}_{5 / 2}$ remains outside from that of the $\mathrm{C} 1 \mathrm{~s}$ region and hence both of them can be analyzed simultaneously in the presence of one another. From the figure, it is clear that in both of the NCs, ruthenium is present in the form of $\mathrm{RuCl}_{3}$ and $\mathrm{RuO}_{3}$ although the atomic

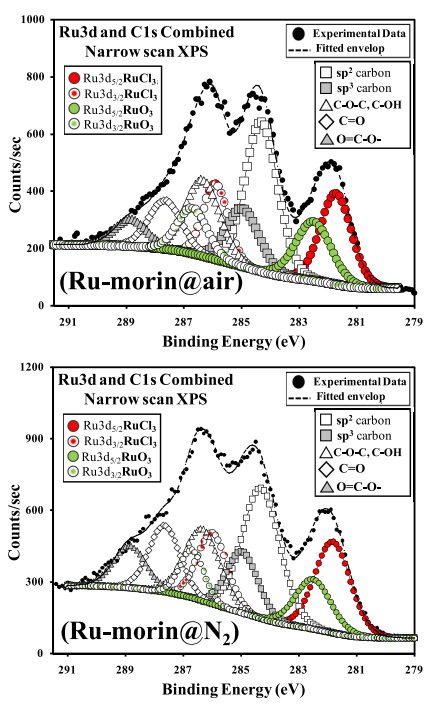

\begin{tabular}{|c|c|c|}
\hline$C_{0,3 / 3 / 0}$ & $\begin{array}{c}\text { Ru- } \\
\text { morin@ } \\
\text { air }\end{array}$ & $\begin{array}{c}\text { Ru- } \\
\text { morin } a \\
\mathbf{N}_{2}\end{array}$ \\
\hline & \multicolumn{2}{|c|}{ Atomic Percentage (\%) } \\
\hline $\mathrm{RuCl}_{3}$ & $\begin{array}{c}58.4 \pm \\
1.1\end{array}$ & $\begin{array}{c}65.0 \pm \\
0.3\end{array}$ \\
\hline $\mathrm{RuO}_{3}$ & $\begin{array}{c}41.6 \pm \\
1.1 \\
\end{array}$ & $\begin{array}{c}35.0 \pm \\
0.3 \\
\end{array}$ \\
\hline $\begin{array}{c}\mathrm{sp}^{2} \\
\text { Carbon }\end{array}$ & $\begin{array}{c}40.4 \pm \\
0.8\end{array}$ & $\begin{array}{c}37.8 \pm \\
0.7\end{array}$ \\
\hline $\begin{array}{c}\mathrm{sp}^{3} \\
\text { Carbon }\end{array}$ & $\begin{array}{c}15.6 \pm \\
0.3\end{array}$ & $\begin{array}{c}15.9 \pm \\
1.4\end{array}$ \\
\hline $\begin{array}{c}\mathrm{C}-\mathrm{O}-\mathrm{C} \\
\mathrm{C}-\mathrm{OH}\end{array}$ & $\begin{array}{c}22.6 \pm \\
0.1\end{array}$ & $\begin{array}{c}19.2 \pm \\
1.2\end{array}$ \\
\hline $\mathrm{C}=\mathrm{O}$ & $\begin{array}{c}13.6 \pm \\
0.4\end{array}$ & $\begin{array}{c}16.8 \pm \\
0.9\end{array}$ \\
\hline$-\mathrm{O}-\mathrm{C}=\mathrm{O}$ & $7.9 \pm 0.6$ & $\begin{array}{c}10.4 \pm \\
0.5\end{array}$ \\
\hline
\end{tabular}

Figure 10. XPS images of Ru-morin@air and Ru-morin@ $\mathrm{N}_{2} \mathrm{NCs}$.

percentages are different. The table associated with Figure 10 reflects the atomic percentages of $\mathrm{RuCl}_{3}$ and $\mathrm{RuO}_{3}$ present in the two NCs. The lower atomic percentage of $\mathrm{RuO}_{3}$ for $\mathrm{Ru}$ morin@ $\mathrm{N}_{2} \mathrm{NC}$ is quite obvious as the material is prepared in inert atmosphere. The participation of morin toward the formation of NCs was also varied upon change in the preparation environment. This was confirmed from the variation of atomic percentage of $\mathrm{sp}^{3}$ carbon, $\mathrm{sp}^{2}$ carbon, $\mathrm{C}=\mathrm{O},-\mathrm{O}-\mathrm{C}=\mathrm{O}$, and $\mathrm{C}-\mathrm{O}-\mathrm{C}$ carbons, as reflected in the table of Figure 10.

ICP-OES Analysis. From the ICP-OES technique, the amount of ruthenium in the catalyst was found to be $1.97 \times$ $10^{-3} \mathrm{~mol} \%$. After the first run, the catalyst was regenerated from the reaction mixture, which was further analyzed for the amount of $\mathrm{Ru}$ that could have been leached from the catalyst during the reaction. It was found that only $1.28 \%$ of $\mathrm{Ru}$ has leached from the catalyst after the first cycle. Therefore, there was a fair possibility of recyclability of the catalyst, which was further confirmed by actually recycling it four times. The experiment is described below.

Catalytic Activity of the Ru-Based NCs. After the synthesis and thorough characterization, the reactivity of the NC was examined for the hydrogenation of nitroarenes to furnish aniline derivatives. We commenced our study by performing a series of experiments to screen the catalysts using nitrobenzene (1a) as the model substrate and sodium borohydride as the reducing agent (Table 3). During our preliminary experiments for the screening of the catalysts, $\mathrm{Ru}$ morin NC formed under nitrogen atmosphere (Ru-morin@

Table 3. Screening of the Catalysts for the Nitrobenzene Reduction Using $\mathrm{NaBH}_{4}{ }^{a}$

\begin{tabular}{clcc} 
entry & \multicolumn{1}{c}{ catalyst } & time $(\mathrm{h})$ & yield $^{b}(\%)$ \\
1 & $\mathrm{Ru}-$ morin@air & 1.5 & 86 \\
2 & $\mathrm{Ru}-\mathrm{morin} @ \mathrm{~N}_{2}$ & 1.5 & 91 \\
3 & $\mathrm{RuCl}_{3} \cdot x \mathrm{H}_{2} \mathrm{O}$ & 1.5 & 87 \\
$4^{c}$ & morin & 3 &
\end{tabular}

${ }^{a}$ Condition: $\mathrm{PhNO}_{2}(0.1 \mathrm{mmol})$, catalyst $\left(1.97 \times 10^{-3} \mathrm{~mol} \%\right.$ of $\left.\mathrm{Ru}\right)$, $\mathrm{NaBH}_{4}(0.5 \mathrm{mmol})$, water $(1 \mathrm{~mL}), 100{ }^{\circ} \mathrm{C}$, time. ${ }^{b}$ Isolated yield. ${ }^{c} 6$ $\mathrm{mg}$ of catalyst. 
$\mathrm{N}_{2}$ ) produced better product yields than Ru-morin@air (entries 1 and 2, Table 3). This is due to the fact that the $\mathrm{NC}$ entitled as Ru-morin@ $\mathrm{N}_{2}$ has a smaller particle size as well as a larger surface area $\left(24.11 \mathrm{~m}^{2} / \mathrm{g}\right)$ than Ru-morin@air, which help to speed up the reaction rate through the binding of increasingly more reactant molecules over the surface of the NC. Besides, it was interesting to find that the newly synthesized NC (Ru-morin $@ \mathrm{~N}_{2}$ ) is to some extent more reactive than the homogeneous $\mathrm{RuCl}_{3}$ catalyst (entry 3, Table 3). Moreover, reduction reaction using only $6 \mathrm{mg}$ of pristine morin as the active catalyst gave back the substrate $1 \mathrm{a}$ after $3 \mathrm{~h}$ (entry 4, Table 3). This signifies the inactive nature of morin in this reaction.

After screening of the catalyst, Ru-morin@ $\mathrm{N}_{2} \mathrm{NC}$ was employed to optimize the reaction conditions (Table 4). The

Table 4. Screening of Reaction Parameters for Nitrobenzene Reduction Using Ru-morin@ $\mathrm{N}_{2}{ }^{a}$

\begin{tabular}{cclccc} 
entry & cat. $(\mathrm{mg})$ & \multicolumn{1}{c}{ solvent } & $T\left({ }^{\circ} \mathrm{C}\right)$ & $t(\mathrm{~h})$ & yield $(\%)^{b}$ \\
1 & & water & 100 & 1.5 & \\
2 & 6 & EtOH & 65 & 1.5 & 78 \\
3 & 6 & $\mathrm{H}_{2} \mathrm{O} / \mathrm{EtOH}(1: 1)$ & 70 & 1.5 & 82 \\
4 & 6 & DMF & 120 & 1.5 & 60 \\
5 & 6 & toluene & 110 & 1.5 & $<5$ \\
6 & 6 & water & 100 & 1.5 & 91 \\
7 & 6 & water & 50 & 1.5 & 54 \\
8 & 6 & water & $\mathrm{rt}$ & 1.5 & 25 \\
9 & 6 & water & 100 & 1 & 80 \\
10 & 6 & water & 100 & 2 & 92 \\
11 & 2.5 & water & 100 & 1.5 & 81 \\
12 & 12 & water & 100 & 1.5 & $>92$
\end{tabular}

${ }^{a}$ Condition: $\mathrm{PhNO}_{2}(0.1 \mathrm{mmol}), \mathrm{NaBH}_{4}(0.5 \mathrm{mmol}), \mathrm{Ru}$-morin@ $\mathrm{N}_{2}$, solvent $(1.0 \mathrm{~mL}) .{ }^{b}$ Isolated yield.

reaction did not take place without any catalyst that ensures the principal role of the ruthenium $\mathrm{NC}$ in this reduction reaction (entry 1, Table 4). Several solvents, including ethanol, water-ethanol mixture (1:1), toluene, DMF, water, etc. (entries 2-6, Table 4), were screened, but except water, rest of them showed a detrimental effect on the product yield. The reactions were found to proceed satisfactorily under refluxing conditions (entries 6-8, Table 4). Besides, $6 \mathrm{mg}$ of Rumorin@ $\mathrm{N}_{2} \mathrm{NC}\left(1.97 \times 10^{-3} \mathrm{~mol} \%\right.$ of $\left.\mathrm{Ru}\right)$ was found the best for this reduction reaction (entries 6,11-12, Table 4).

Similar to that of the catalyst, reducing agent is also another important parameter for this reaction. The reaction did not furnish any product without any reducing agent (entry 1 , Table 5). Several types of reducing agents were examined for this reaction (Table 5). Among them, $\mathrm{SnCl}_{2}$, D-glucose, D-galactose, ascorbic acid, formic acid, and disodium tartrate remained unsuccessful to furnish any desired products (entries 2-7, Table 5). It was found that hydrazine monohydrate produced only around $60 \%$ yield, while sodium borohydride gives $91 \%$ yield under the same condition (entries 8 and 9, Table 5). The amount of $\mathrm{NaBH}_{4}$ was also screened (entries 9-11, Table 5), and the best result was obtained in the presence of $0.5 \mathrm{mmol}$ $\mathrm{NaBH}_{4}$ using $6 \mathrm{mg}$ of Ru-morin@N $\mathrm{N}_{2}\left(1.97 \times 10^{-3} \mathrm{~mol} \%\right.$ of $\mathrm{Ru})$ in water as the green solvent after $1.5 \mathrm{~h}$ of stirring under refluxing conditions.

After the attainment of the best reaction conditions, scope and efficiency of this methodology were further extended for the reduction of several substituted nitrobenzenes. Except
Table 5. Screening of Reaction Parameters for Nitrobenzene Reduction Using Ru-morin@ $\mathrm{N}_{2}{ }^{a}$

\begin{tabular}{cll} 
entry & \multicolumn{1}{c}{ reducer } & yield $(\%)^{b}$ \\
1 & & \\
2 & SnCl $_{2}$ & \\
3 & D-glucose & \\
4 & D-galactose & \\
5 & ascorbic acid & \\
6 & formic acid & \\
7 & disodium tartrate & 58 \\
8 & hydrazine monohydrate & 91 \\
9 & $\mathrm{NaBH}_{4}$ & 79 \\
$10^{c}$ & $\mathrm{NaBH}_{4}$ & 90 \\
$11^{d}$ & $\mathrm{NaBH}_{4}$ &
\end{tabular}

${ }^{a}$ Condition: $\mathrm{PhNO}_{2}(0.1 \mathrm{mmol}), \mathrm{Ru}-\mathrm{morin} @ \mathrm{~N}_{2}\left(6 \mathrm{mg}, 1.97 \times 10^{-3}\right.$ mol \% of $\mathrm{Ru})$, reducing agent $(0.5 \mathrm{mmol})$, water $(1.0 \mathrm{~mL}), 100{ }^{\circ} \mathrm{C}$, 1.5 h. ${ }^{b}$ Isolated yield. ${ }^{c} 0.25 \mathrm{mmol} \mathrm{NaBH}_{4} \cdot{ }^{d} 1.0 \mathrm{mmol} \mathrm{NaBH}_{4}$.

aniline products, no side products were formed during the course of this reduction reaction, which undoubtably signifies the selectivity of our newly synthesized methodology. The results are given in Table 6. Substrates having the phenyl ring

Table 6. Synthesis of Aniline Derivatives ${ }^{a, b, c, d}$

\begin{tabular}{|l|l|l|l|l|l|}
\hline Entry & Substrates & Products $^{\mathbf{b}}$ & $\begin{array}{c}\text { Time } \\
(\mathbf{m i n})\end{array}$ & $\begin{array}{c}\text { Yields } \\
(\%)^{\mathbf{c}}\end{array}$ & $\begin{array}{c}\text { TOF } \\
\left(\mathbf{m i n}^{-1}\right)^{\mathbf{d}}\end{array}$ \\
\hline 1 & & 90 & 91 & 513 \\
\hline 2 & & &
\end{tabular}

${ }^{a}$ Conditions: $\mathrm{PhNO}_{2}(0.1 \mathrm{mmol}), \mathrm{Ru}-\mathrm{morin} @ \mathrm{~N}_{2}\left(6 \mathrm{mg}, 1.97 \times 10^{-3}\right.$ mol \% of $\mathrm{Ru}), \mathrm{NaBH}_{4}(0.5 \mathrm{mmol})$, water $(1.0 \mathrm{~mL}), 100{ }^{\circ} \mathrm{C}$, time. ${ }^{b}$ NMR spectra are given in the Supporting Information (Figures S5S9). ${ }^{c}$ Isolated yields. ${ }^{d} \mathrm{TOF}=\mathrm{TON} /$ time $[\mathrm{TON}=$ moles of substrate converted per mole of active site].

substituted by electron-donating groups as well as electronwithdrawing groups bestowed good to best product yields using our optimized reaction conditions. Reduction of 1methyl-3-nitrobenzene and 1-methoxy-2-nitrobenzene produced their corresponding amino products with 93 and $91 \%$ yields (entries 2 and 3, Table 6). The nitro group of 1-bromo3 -nitrobenzene was successfully reduced to furnish the amino product 3-bromoaniline with $89 \%$ yield (entry 4 , Table 6 ). Our optimized reaction condition was found to be very selective toward the nitro group, keeping the $-\mathrm{CN}$ group unaffected in the case of 4-nitrobenzonitrile (entry 5, Table 6). 


\section{RECYCLABILITY}

Capability of recycle and reuse are the principal advantages of a heterogeneous catalyst. To examine the recycling efficiency of the NCs, reduction reaction was performed using nitrobenzene as the model substrate. The recyclability chart of the NCs is presented in Figure 11. Further, the stability of the reused

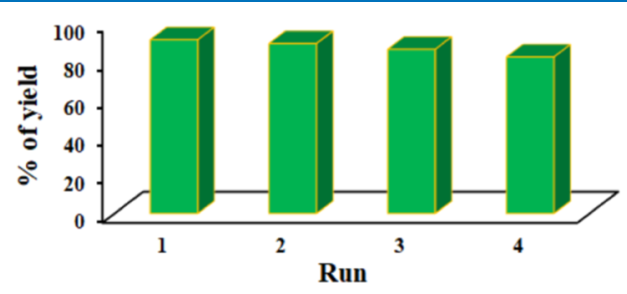

Figure 11. Recycling efficiency of Ru-morin@ $\mathrm{N}_{2} \mathrm{NC}$.

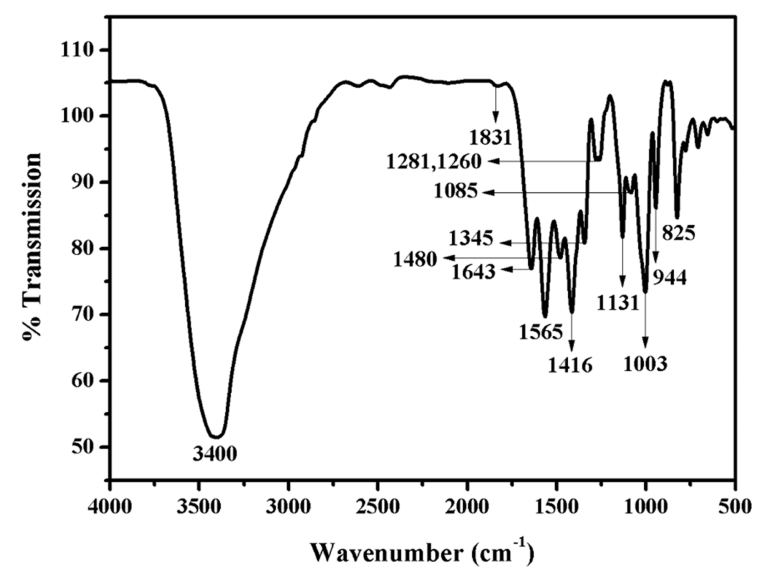

Figure 12. FTIR of the reused Ru-morin@ $\mathrm{N}_{2} \mathrm{NC}$.

Table 7. FTIR Spectral Data of Ru-morin@ $\mathrm{N}_{2}$ NCs and After Four Catalyst Cycles

$\begin{array}{cc}\text { initial peak position }\left(\mathrm{cm}^{-1}\right) & \text { peak position }\left(\mathrm{cm}^{-1}\right) \text { after reuse } \\ 3440 & 3400 \\ 1805 & 1831 \\ 1625 & 1643 \\ 1515 & 1565,1480 \\ 1417 & 1416 \\ 1321 & 1345,1281,1260 \\ 1237 & \\ 1182 & 1131 \\ 1099 & 1085 \\ 989 & 1003,944 \\ 836 & 825\end{array}$

catalyst was examined by FTIR analysis (Figure 12) (Table 7), and from this spectrum and the table, it is quite clear that the newly synthesized Ru-morin@ $\mathrm{N}_{2} \mathrm{NC}$ is significantly stable up to four cycles without a considerable loss in its activity.

The importance and efficiency of our methodology were compared to the literature reports.

\section{CONCLUSION}

In conclusion, a newly designed ruthenium-based nanocatalyst has been synthesized through a mild and eco-friendly methodology under inert atmosphere. Interestingly, the nanocatalyst provides excellent catalytic activity for the synthesis of several substituted anilines using water as green solvent. Our newly generated methodology showcases a number of advantages: (a) significantly lower time of reaction; (b) use of water as green solvent; (c) scope of wide functionalization; (d) small particle size of the NC; (e) ease of catalyst as well as product separation; (f) excellent turnover frequency; and ( $\mathrm{g}$ ) hassle-free technique for the synthesis of the NC. We have summarized a comparison of our work with the previously reported reduction methodologies of similar aromatic nitro compounds using Ru-based catalyst in Table 8 . The all round advantage of water-based catalyst generation and reaction conditions together with a wide suitable ratio of reducing agent to starting material, product yield, and catalyst reusability make the method fairly attractive.

\section{EXPERIMENTAL SECTION}

Materials. Ruthenium(III) chloride hydrate $\left(\mathrm{RuCl}_{3} \cdot x \mathrm{H}_{2} \mathrm{O}\right.$, MW: 207.43), morin hydrate [(2-(2,4-dihydroxyphenyl)-3,5,7trihydroxychromen-4-one)], nitrobenzene $(\geq 99.0 \%)$, and $\mathrm{CDCl}_{3}$ were obtained from Sigma-Aldrich. All other reagents required for this study were of AR grade and used as obtained. All of the solvents used were distilled and dried before the actual use. Triple-distilled water was used throughout the experiment.

Apparatus. Absorption spectral data were acquired using PerkinElmer Lambda 25 UV-Vis spectrophotometer. Nitrogen adsorption-desorption isotherms were analyzed at liquid nitrogen temperature $(77 \mathrm{~K})$ using a Quantachrome surface area analyzer. The specific surface area and pore diameter were calculated using the Brunauer-Emmett-Teller (BET) method. Transmission electron microscopy (TEM) images were obtained using a Jeol JEM $2100 \mathrm{HR}$ with electron energy loss spectroscopy (EELS). Fourier transform infrared (FTIR) spectra of the samples were recorded in the range 400-4000 $\mathrm{cm}^{-1}$ on a PerkinElmer FT-IR 783 spectrophotometer having a resolution of $1 \mathrm{~cm}^{-1}$ and PerkinElmer FT-IR Spectrum Two Spectrophotometer having a resolution of $0.5 \mathrm{~cm}^{-1}$ using $\mathrm{KBr}$ pellets. A Mettler Toledo digital balance correct up to fourth decimal place was used for measuring the weights. A centrifuge machine Remi Elektrotechnik Ltd. R-4C was used to separate the supernatant solution of the nanoparticle. X-ray diffraction (XRD) was measured using X-PERT-PRO Panalytical diffractometer to confirm the actual phase of the prepared material. X-ray photoelectron spectroscopy (XPS) measurement was carried out using a Thermo Scientific Escalab $250 \mathrm{Xi}$ system. The hydrodynamic radii of the NCs were estimated using Malvern Zetasizer Nano S, model ZEN 1600 dynamic light scattering (DLS) instrument. The thermogravimetric analysis of the NCs was conducted using Diamond TG/DTA Thermogravimetric/Differential Thermal Analyzer of PerkinElmer Instruments in the temperature range of $28-439{ }^{\circ} \mathrm{C}$. A digital Mettler Toledo Seven Compact $\mathrm{pH} /$ ion meter was used to measure and adjust the $\mathrm{pH}$ of the solutions. The mol \% of ruthenium present in the NCs was estimated using ICP-OES instrument (ICAP duo 6500, Thermo Fisher Scientific; RF power, $1150 \mathrm{~W}$; flush pump rate, $50 \mathrm{rpm}$; analysis pump rate, $50 \mathrm{rpm}$; auxiliary gas flow, $1.0 \mathrm{~L} / \mathrm{min}$, Nebulizer gas flow, 0.60 $\mathrm{L} / \mathrm{min}$; coolant gas flow, $12 \mathrm{~L} / \mathrm{min}$; and wavelength, 287.876 $\mathrm{nm})$. Thin-layer chromatography (TLC) analysis was performed on TLC silica gel $60 \mathrm{~F}_{254}$. The products were purified using silica gel (60-120 mesh) column chromatography. NMR spectra were recorded on a 300 and $400 \mathrm{MHz}$ 


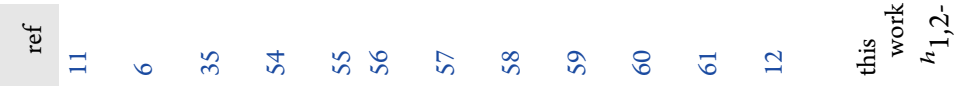

㟧爱的

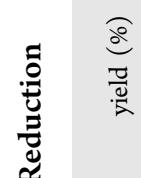

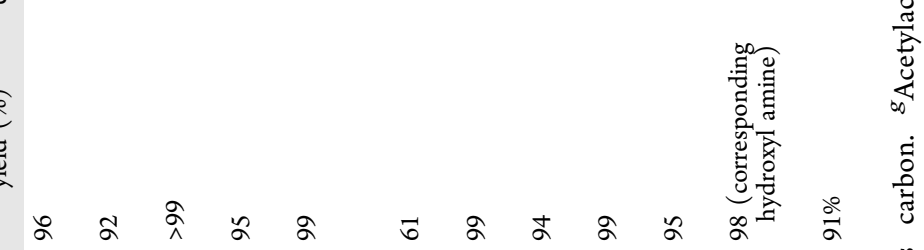

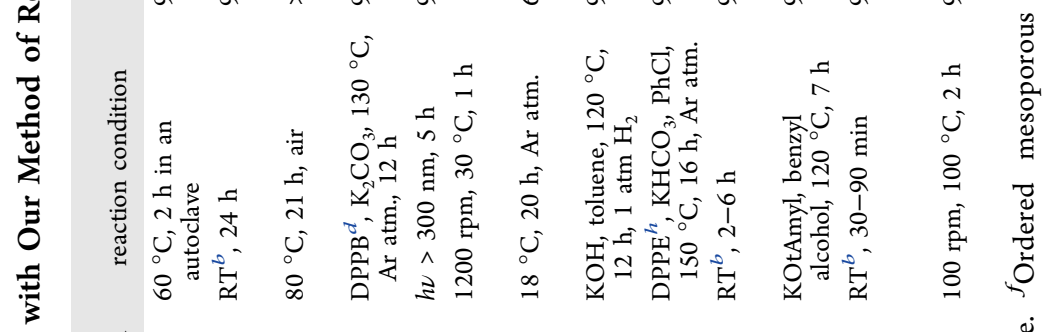

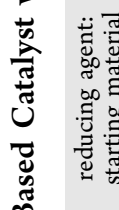

可

$\overrightarrow{\ddot{\theta}}$

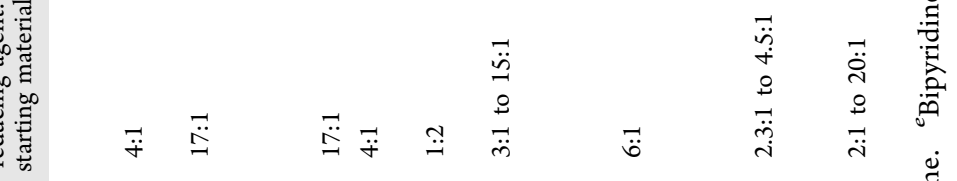

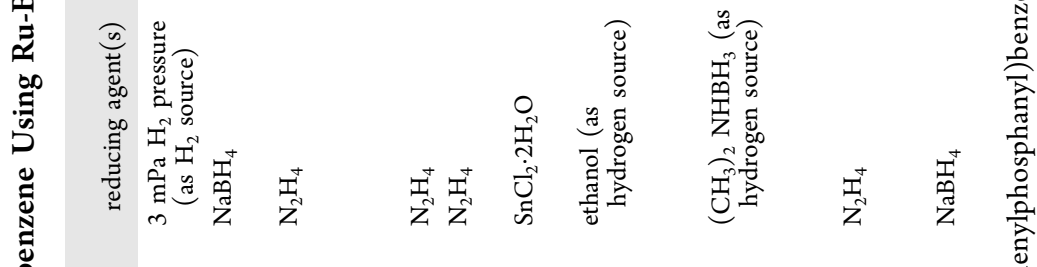

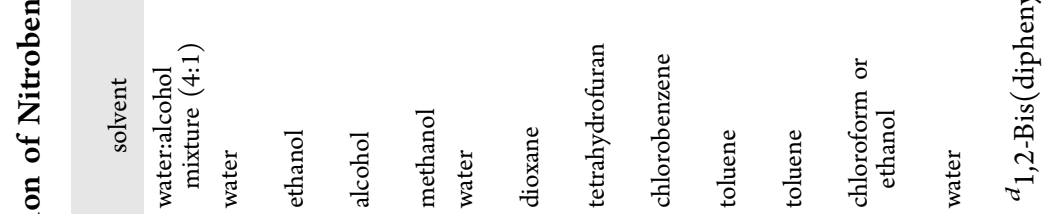

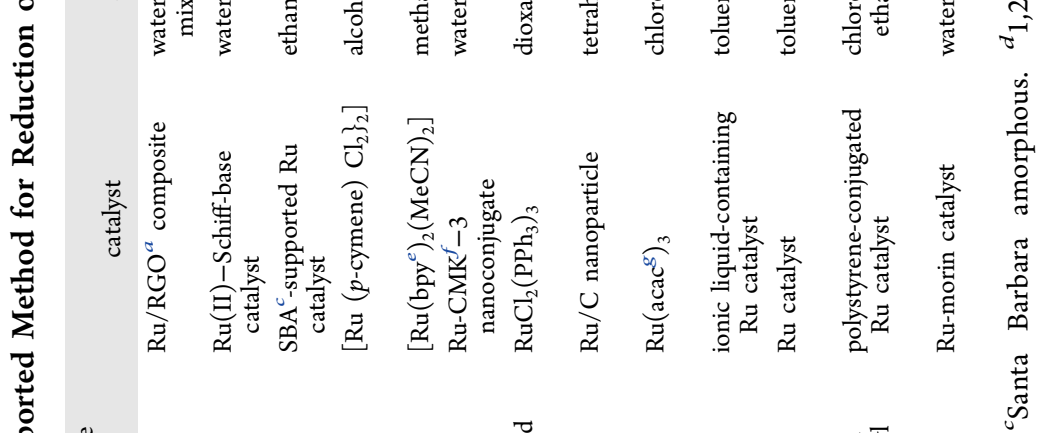

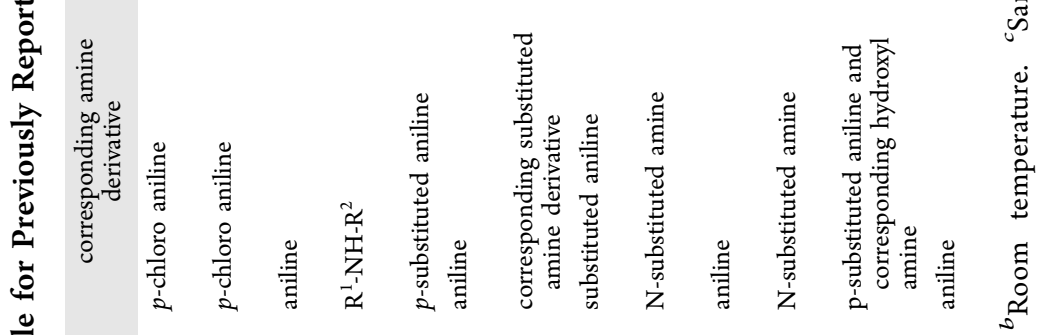

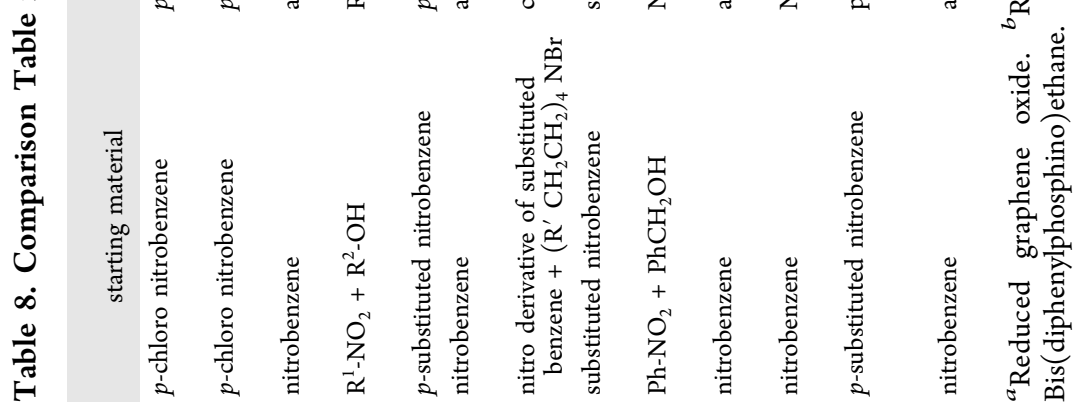


NMR instrument using $\mathrm{CDCl}_{3}$ as solvents. The ${ }^{1} \mathrm{H}$ chemical shifts are reported in ppm relative to TMS.

Synthesis of Ruthenium NCs at Open Atmosphere (Ru-morin@air). Initially, $5 \mathrm{~mL}$ of $10 \mathrm{mM}$ aqueous solution of $\mathrm{RuCl}_{3}$ was prepared at $\sim 18{ }^{\circ} \mathrm{C}$. Then, it was added to $5 \mathrm{~mL}$ of $10 \mathrm{mM}$ ethanolic solution of morin. Thereafter, the resulting solution was kept undisturbed overnight after adjusting the $\mathrm{pH}$ to $\sim 12$ using $\mathrm{NaOH}$ solution. The solution was then centrifuged at $2000 \mathrm{rpm}$ for $10 \mathrm{~min}$, and the supernatant solution was discarded. The residue was washed several times with a water:EtOH (1:1) mixture until the washing was colorless. Finally, the solid NC, designated as Ru-morin@air, was dried and taken for characterization and application.

Synthesis of Ruthenium NCs under $\mathrm{N}_{2}$ Atmosphere $\left(\mathrm{Ru}-\mathrm{morin} @ \mathrm{~N}_{2}\right)$. The synthesis procedure of this case is similar to that of Ru-morin@air. The only difference lies in the atmospheric condition of synthesis. Here, preparation of all of the solutions and the total synthesis procedure were carried out in a glovebox under $\mathrm{N}_{2}$ atmosphere. As in the previous case, the NC was washed several times with a water:EtOH (1:1) mixture and finally dried before taking out of the $\mathrm{N}_{2}$ atmosphere and designated as Ru-morin@ $\mathrm{N}_{2}$.

\section{ASSOCIATED CONTENT}

\section{S Supporting Information}

The Supporting Information is available free of charge at https://pubs.acs.org/doi/10.1021/acsomega.9b02770.

UV interaction between morin and ruthenium at $\mathrm{pH} 5$, 7, and 9; PXRD pattern of Ru-NCs; ${ }^{1} \mathrm{H}$ and ${ }^{13} \mathrm{C}$ NMR spectra of the synthesized products; and related references (PDF)

\section{AUTHOR INFORMATION}

\section{Corresponding Author}

*E-mail: kamalchem.roy@gmail.com.

\section{ORCID}

Kamalika Sen: 0000-0003-1005-5147

\section{Notes}

The authors declare no competing financial interest.

\section{ACKNOWLEDGMENTS}

P.S. express sincere thanks to University Grants Commission (UGC) (Ref no. of PS 20/12/2015(ii)EU-V dated 24.08.2016) for providing necessary fellowship. The authors also express their sincere gratitude to Nayan Ranjan Saha, Department of Chemical Technology, University of Calcutta, India, for measuring the XRD analysis. They are also thankful to Dipak Chandra Konar, Technical Officer-I, Chemistry, Bose Institute, Main Campus, for measuring DLS of their samples. They would like to express their sincere gratitude to Prof. Susanta Lahiri, Chemical Science Division, Saha Institution for Nuclear Physics, India, and his fellow Nabanita Naskar for measuring ICP of our sample to determine the mol percentage of the NC. They are thankful to Dr. Dipankar Chattopadhyay, Department of Polymer Science and Technology, University of Calcutta, India, for obtaining FTIR spectra of the reused catalyst.

\section{REFERENCES}

(1) Takale, B. S.; Bao, M.; Yamamoto, Y.; Almansour, A. I.; Arumugam, N.; Kumar, R. S. Applications of Metal Nanopore Catalysts in Organic Synthesis. Syn. Lett. 2015, 26, 2355-2380.
(2) Hudson, R.; Feng, Y.; Varma, R. S.; Moores, A. Bare magnetic nanoparticles: sustainable synthesis and applications in catalytic organic transformations. Green Chem. 2014, 16, 4493-4505.

(3) Zaera, F. Nanostructured materials for applications in heterogeneous catalysis. Chem. Soc. Rev. 2013, 42, 2746-2762.

(4) Halder, M.; Islam, M. M.; Ansari, Z.; Ahammed, S.; Sen, K.; Islam, $\mathrm{S}$. M. Biogenic nano-CuO-catalyzed facile $\mathrm{C}-\mathrm{N}$ cross-coupling reactions: scope and mechanism. ACS Sustainable Chem. Eng. 2017, 5, 648-657.

(5) Halder, M.; Islam, M. M.; Singh, P.; Roy, A. S.; Islam, S. M.; Sen, K. Sustainable Generation of $\mathrm{Ni}(\mathrm{OH})_{2}$ Nanoparticles for the Green Synthesis of 5-Substituted $1 \mathrm{H}$-Tetrazoles: A Competent Turn on Fluorescence Sensing of $\mathrm{H}_{2} \mathrm{O}_{2}$. ACS Omega 2018, 3, 8169-8180.

(6) Jia, W.-G.; Zhang, H.; Zhang, T.; Xie, D.; Ling, S.; Sheng, E.-H. Half-sandwich ruthenium complexes with Schiff-base ligands: Syntheses, characterization, and catalytic activities for the reduction of nitroarenes. Organometallics 2016, 35, 503-512.

(7) Tiruwa, R. A review on nanoparticles-preparation and evaluation parameters. Indian J. Pharm. Biol. Res. 2015, 4, 27-31.

(8) Ealias, A. M.; Saravanakumar, M. P. A review on the classification, characterization, synthesis of nanoparticles and their application. IOP Conf. Ser.: Mater. Sci. Eng. 2017, 263, 32019-32033.

(9) Lara, P.; Philippot, K.; Chaudret, B. Organometallic ruthenium nanoparticles: a comparative study of the influence of the stabilizer on their characteristics and reactivity. Chem. Cat. Chem. 2012, 5, 28-45.

(10) Salas, G.; Campbell, P. S.; Santini, C. C.; Philippot, K.; Gomes, M. F. C.; Pádua, A. A. H. Ligand effect on the catalytic activity of ruthenium nanoparticles in ionic liquids. Dalton Trans. 2012, 41, 13919-13926.

(11) Fan, G.-Y.; Huang, W.-J. Synthesis of ruthenium/reduced graphene oxide composites andapplication for the selective hydrogenation of halonitroaromatics. Chin. Chem. Lett. 2014, 25, 359-363.

(12) Tyler, J. H.; Nazari, S. H.; Patterson, R. H.; Udumula, V.; Smith, S. J.; Michaelis, D. J. Synthesis of N-aryl and N-heteroaryl hydroxylamines via partial reduction of nitroarenes with soluble nanoparticle catalysts. Tetrahedron Lett. 2017, 58, 82-86.

(13) Kannan, S. K.; Sundrarajan, M. Green synthesis of ruthenium oxide nanoparticles: Characterization and its antibacterial activity. Adv. Powder Technol. 2015, 26, 1505-1511.

(14) Ismail, E.; Khamlich, S.; Dhlamini, M.; Maaza, M. Green biosynthesis of ruthenium oxide nanoparticles on nickel foam as electrode material for supercapacitor applications. RSC Adv. 2016, 6, 86843-86850.

(15) Zhou, Y.; Xu, M.; Liu, Y.; Bai, Y.; Deng, Y.; Liu, J.; Chen, L. Green synthesis of $\mathrm{Se} / \mathrm{Ru}$ alloy nanoparticles using gallic acid and evaluation of theiranti-invasive effects in HeLa cells. Colloids Surf., $B$ 2016, 144, 118-124.

(16) Ni, X.; Zhang, B.; Li, C.; Pang, M.; Su, D.; Williams, C. T.; Liang, C. Microwave-assisted green synthesis of uniform Ru nanoparticles supported on non-functional carbon nanotubes for cinnamaldehyde hydrogenation. Catal. Commun. 2012, 24, 65-69.

(17) Zhao, J.; Hu, W.; Li, H.; Ji, M.; Zhao, C.; Wang, Z.; Hu, H. One-step green synthesis of a ruthenium/graphene composite as a highly efficient catalyst. RSC Adv. 2015, 5, 7679-7686.

(18) García-Peña, N. G.; Redón, R.; Herrera-Gomez, A.; FernándezOsorio, A. L.; Bravo-Sanchez, M.; Gomez-Sosa, G. Solventless synthesis of ruthenium nanoparticles. Appl. Surf. Sci. 2015, 340, $25-34$.

(19) Taşçı, E.; Akbayrak, S.; Özkar, S. Ruthenium (0) nanoparticles supported on silica coated $\mathrm{Fe}_{3} \mathrm{O}_{4}$ as magnetically separable catalysts for hydrolytic dehydrogenation of ammonia borane. Int. J. Hydrogen Energy 2018, 43, 15124-15134.

(20) Jagadeesh, R. V.; Surkus, A.-E.; Junge, H.; Pohl, M.-M.; Radnik, J.; Rabeah, J.; Huan, H.; Schünemann, V.; Brückner, A.; Beller, M. Nanoscale Fe2O3-based catalysts for selective hydrogenation of nitroarenes to anilines. Science 2013, 342, 1073-1076.

(21) Wei, H.; Liu, X.; Wang, A.; Zhang, L.; Qiao, B.; Yang, X.; Huang, Y.; Miao, S.; Liu, J.; Zhang, T. $\mathrm{FeO}_{\mathrm{x}}$-supported platinum single-atom and pseudo-single-atom catalysts for chemoselective 
hydrogenation of functionalized nitroarenes. Nat. Commun. 2014, 5, 5634-5641.

(22) Tafesh, A. M.; Weiguny, J. A review of the selective catalytic reduction of aromatic nitro compounds into aromatic amines, isocyanates, carbamates, and ureas using CO. Chem. Rev. 1996, 96, $2035-2052$.

(23) Radl, S.; Koynov, A.; Tryggvason, G.; Khinast, J. G. DNS-based prediction of the selectivity of fast multiphase reactions: Hydrogenation of nitroarenes. Chem. Eng. Sci. 2008, 63, 3279-3291.

(24) Lawrence, S. A. Amines: Synthesis, Properties and Applications; Cambridge University Press: Cambridge, 2004.

(25) Travis, S.; Rappoport, Z. The Chemistry of Anilines; John Wiley \& Sons, Ltd.: Chichester, 2007.

(26) Rai, R. K.; Mahata, A.; Mukhopadhyay, S.; Gupta, S.; Li, P.-Z.; Nguyen, K. T.; Zhao, Y.; Pathak, B.; Singh, S. K. Room-temperature chemoselective reduction of nitro groups using non-noble metal nanocatalysts in water. Inorg. Chem. 2014, 53, 2904-2909.

(27) Liu, J.; Cui, J.; Vilela, F.; He, J.; Zeller, M.; Hunter, A. D.; Xu, Z. In situ production of silver nanoparticles on an aldehyde-equipped conjugated porous polymer and subsequent heterogeneous reduction of aromatic nitro groups at room temperature. Chem. Commun. 2015, 51, 12197-12200.

(28) Jia, W.-G.; Dai, Y.-C.; Zhang, H.-N.; Lu, X.; Sheng, E.-H. Synthesis and characterization of gold complexes with pyridine-based SNS ligands and as homogeneous catalyst for reduction of 4nitrophenol. RSC Adv. 2015, 5, 29491-29496.

(29) Zhao, Z.; Yang, H.; Li, Y.; Guo, X. Cobalt-modified molybdenum carbide as an efficient catalyst for chemoselective reduction of aromatic nitro compounds. Green Chem. 2014, 16, 1274-1281.

(30) Yang, X.-J.; Chen, B.; Zheng, L.-Q.; Wu, L.-Z.; Tung, C.-H. Highly efficient and selective photocatalytic hydrogenation of functionalized nitrobenzenes. Green Chem. 2014, 16, 1082-1086.

(31) Liu, X.; Ye, S.; Li, H.-Q.; Liu, Y.-M.; Cao, Y.; Fan, K.-N. Mild, selective and switchable transfer reduction of nitroarenes catalyzed by supported gold nanoparticles. Catal. Sci. Technol. 2013, 3, 32003206.

(32) de Noronha, R. G.; Romão, C. C.; Fernandes, A. C. Highly chemo-and regioselective reduction of aromatic nitro compounds using the system silane/oxo-rhenium complexes. J. Org. Chem. 2009, 74, 6960-6964.

(33) Jansat, S.; Picurelli, D.; Pelzer, K.; Philippot, K.; Gomez, M.; Muller, G.; Lecante, P.; Chaudret, B. Synthesis, characterization and catalytic reactivity of ruthenium nanoparticles stabilized by chiral $\mathrm{N}$ donor ligands. New J. Chem. 2006, 30, 115-122.

(34) Tomkins, P.; Gebauer-Henke, E.; Leitner, W.; Müller, T. E. Concurrent hydrogenation of aromatic and nitro groups over carbonsupported ruthenium catalysts. ACS Catal. 2015, 5, 203-209.

(35) Carrillo, A. I.; Stamplecoskie, K. G.; Marin, M. L.; Scaiano, J. C. 'From the mole to the molecule': ruthenium catalyzed nitroarene reduction studied with 'bench', high-throughput and single molecule fluorescence techniques. Catal. Sci. Technol. 2014, 4, 1989-1996.

(36) Indra, A.; Maity, N.; Maity, P.; Bhaduri, S.; Lahiri, G. K. Control of chemoselectivity in hydrogenations of substituted nitroand cyano-aromatics by cluster-derived ruthenium nanocatalysts. $J$. Catal. 2011, 284, 176-183.

(37) Panhwar, Q. K.; Memon, S. Synthesis of Cr (III)-morin complex: Characterization and antioxidant study. Sci. World J. 2014, 2014, 1-9.

(38) Ghatak, S. K.; Dey, D.; Sen, S.; Sen, K. Aromatic amino acids in high selectivity bismuth (III) recognition. Analyst 2013, 138, 23082314.

(39) Thanh, N. T. K.; Maclean, N.; Mahiddine, S. Mechanisms of nucleation and growth of nanoparticles in solution. Chem. Rev. 2014, 114, 7610-7630.

(40) Sudarsanam, P.; Peeters, E.; Makshina, V. E.; Parvulescu, V. I.; Sels, B. F. Advances in porous and nanoscale catalysts for viable biomass conversion. Chem. Soc. Rev. 2019, 48, 2366-2421.
(41) Isaacs, M. A.; Robinson, N.; Barbero, B.; Durndell, L. J.; Manayil, J. C.; Parlett, C. M. A.; D’Agostino, C.; Wilson, K.; Lee, A. F. Unravelling mass transport in hierarchically porous catalysts. J. Mater. Chem. A. 2019, 7, 11814-11825.

(42) Thommes, M.; Kaneko, K.; Neimark, A. V.; Olivier, J. P.; Rodriguex-Reinoso, F.; Rouquerol, J.; Sing, K. S. W. Physisorption of gases, with special reference to the evaluation of surface area and pore size distribution (IUPAC Technical Report). Pure Appl. Chem. 2015, 87, 1051-1069.

(43) Alp, E.; Aydogan, N. A comparative study: synthesis of superparamagnetic iron oxide nanoparticles in air and $\mathrm{N}_{2}$ atmosphere. Colloids Surf., A 2016, 510, 205-212.

(44) Stari, C.; Cichetto, L., Jr.; Peres, C. H. M. A.; Rivera, V. A. G.; Sergeenkov, S.; Cardoso, C. A.; Marega, E.; Araújo-Moreira, F. M. Comparative study on structure and magnetic properties of polycrystalline $\mathrm{Pr}_{\mathrm{x}} \mathrm{Y}_{1}-\mathrm{xBa}_{2} \mathrm{Cu}_{3} \mathrm{O}_{7}-\delta$ prepared in oxygen and argon atmosphere. J. Alloys Compd. 2012, 528, 135-140.

(45) Fuloria, N. K.; Fuloria, S. Spectroscopy: Fundamantals and Data Interpretation; Studium Press India Pvt. Ltd., 2013.

(46) Shah, M. P. Exploited application of Lactobacillus in microbial degradation and decolorization of acid orange. Int. J. 2014, 2, 160166.

(47) Stammer, C.; Taurins, A. Infrared spectra of phenazines. Spectrochim. Acta 1963, 19, 1625-1653.

(48) Gilbert, A. S. In Encyclopedia of Spectroscopy and Spectrometry. Academic Press: U.K.; 1999, pp 1035-1048.

(49) Mary, Y. S.; Jojo, P. J.; Alsenoy, C. V.; Kaur, M.; Siddegowda, M. S.; Yathirajan, H. S.; Nogueira, H. I. S.; Cruz, S. M. A. Vibrational spectroscopic (FT-IR, FT-Raman, SERS) and quantum chemical calculations of 3-(10, 10-dimethyl-anthracen-9-ylidene)-N, N, Ntrimethylpropanaminiium chloride (Melitracenium chloride). Spectrochim. Acta, Part A 2014, 120, 370-380.

(50) Logacheva, N. M.; Baulin, V. E.; Tsivadze, A.; Pyatova, E. N.; Ivanova, I. S.; Velikodny, Y. A.; Chernyshev, V. V. Ni (II), Co (II), Cu (II), Zn (II) and $\mathrm{Na}$ (I) complexes of a hybrid ligand 4'-(4"' -benzo15-crown-5)-methyloxy-2, 2': 6', 2 "-terpyridine. Dalton Trans. 2009, 14, 2482-2489.

(51) Yadav, R. A.; Dixit, V.; Yogesh, M.; Santhosh, C. Raman and IR spectral and DFT based vibrational and electronic characterization of isolated and zwitterionic forms of L-tyrosin. Pharm. Anal. Acta 2015, $6,1-18$.

(52) Husin, M. R.; Arsad, A.; Suradi, S. S.; Alothman, O.; Ngadi, N.; Kamaruddin, M. J. Fourier transforms infrared spectroscopy and X-ray diffraction investigation of recycled polypropylene/polyaniline blends. Chem. Eng. Trans. 2017, 56, 1015-1020.

(53) Ansari, Z.; Saha, A.; Singha, S. S.; Sen, K. Phytomediated generation of $\mathrm{Ag}, \mathrm{CuO}$ and $\mathrm{Ag}-\mathrm{Cu}$ nanoparticles for dimethoate sensing. J. Photochem. Photobiol., A 2018, 367, 200-211.

(54) Cui, X.; Zhang, Y.; Shi, F.; Deng, Y. Ruthenium-catalyzed nitro and nitrile compounds coupling with alcohols: Alternative route for N-substituted amine synthesis. Chem. - Eur. J. 2011, 17, 2587-2591.

(55) Hirao, T.; Shiori, J.; Okahata, N. Ruthenium-bipyridine complex-catalyzed photo-induced reduction of nitrobenzenes with hydrazine. Bull. Chem. Soc. Jpn. 2004, 77, 1763-1764.

(56) Hu, J.; Ding, Y.; Zhang, H.; Wu, P.; Li, X. Highly effective Ru/ CMK-3 catalyst for selective reduction of nitrobenzene derivatives with $\mathrm{H}_{2} \mathrm{O}$ as solvent at near ambient temperature. RSC Adv. 2016, 6, 3235-3242.

(57) Cho, C. S.; Kim, T. K.; Choi, H.-J.; Kim, T.-J.; Shim, S. C. Ruthenium-catalyzed consecutive reduction and cyclization of nitroarenes with tetraalkylammonium bromides leading to quinolines. Bull. Korean Chem. Soc. 2002, 23, 541-542.

(58) Kim, J. H.; Park, J. H.; Chung, Y. K.; Park, K. H. Ruthenium nanoparticle-catalyzed, controlled and chemoselective hydrogenation of nitroarenes using ethanol as a hydrogen source. Adv. Synth. Catal. 2012, 354, 2412-2418.

(59) Liu, Y.; Chen, W.; Feng, C.; Deng, G. Ruthenium-catalyzed one-pot aromatic secondary amine formation from nitroarenes and alcohols. Chem. Asian J. 2011, 6, 1142-1146. 
(60) Patil, N. M.; Sasaki, T.; Bhanage, B. M. Immobilized ruthenium metal-containing ionic liquid-catalyzed dehydrogenation of dimethylamine borane complex for the reduction of olefins and nitroarenes. RSC Adv. 2016, 6, 52347-52352.

(61) Suntrup, L.; Hohloch, S.; Sarkar, B. Expanding the scope of chelating triazolylidenes: mesoionic carbenes from the 1, 5-"Click"regioisomer and catalytic synthesis of secondary amines from nitroarenes. Chem. - Eur. J. 2016, 22, 18009-180018. 